\title{
Educação escolar durante a pandemia: quais lições aprenderemos?
}

\section{School education during the pandemic: what lessons will we learn?}

\section{Educación escolar durante la pandemia: ¿qué lecciones aprenderemos?}

Claudia Amorim Francez Niz'

https://orcid.org/0000-0002-2860-2244

Thaís Cristina Rodrigues Tezani²

https://orcid.org/0000-0002-060 I-1865

\begin{abstract}
Resumo: $O$ novo coronavírus, causou a pandemia da Covid-19, gerando uma série de impactos epidemiológicos e socioeconômicos, sendo necessário o isolamento social para conter o avanço da doença. Em razão disto, as escolas foram fechadas, e surgiu o Ensino Remoto Emergencial, visando a continuidade da aprendizagem dos alunos. Assim, foi realizada uma pesquisa bibliográfica, com o objetivo de analisar as possibilidades da organização da educação escolar durante a pandemia, as características do Ensino Remoto Emergencial e suas implicações para a aprendizagem dos alunos. A partir dos resultados indicados, infere-se que as decorrências são discrepantes, e ainda imensuráveis, uma vez que o Ensino Remoto Emergencial alcança apenas uma parcela dos alunos e evidencia que é um desafio o uso das tecnologias digitais como ferramentas no processo de ensino e aprendizagem.
\end{abstract}

Palavras-chave: Pandemia. Ensino remoto emergencial. Educação à distância.

\begin{abstract}
The new coronavirus caused the Covid-19 pandemic, generating a series of epidemiological and socioeconomic impacts, requiring social isolation to contain the disease's progress. As a result, schools were closed, and Emergency Remote Education emerged, aiming at continuing student learning. Therefore, a bibliographic research was carried out, with the objective of analyzing the possibilities of organizing school education during the pandemic, the characteristics of Emergency Remote Education and its implications for students' learning. From the indicated results, it is inferred that the consequences are different, and still immeasurable, since Emergency Remote Education reaches only a portion of the students and shows that it is a challenge to use digital technologies as tools in the teaching process and learning.
\end{abstract}

\footnotetext{
' Mestre em Educação Escolar pela UNESP- Universidade Estadual Paulista. Docente na rede municipal de educação de Bauru-SP. E-mail: cacaunesp@gmail.com.

${ }^{2}$ Doutora em Educação pela UFScar- Universidade Federal de São Carlos. Docente da Faculdade de Ciências da UNESP -Universidade Estadual Paulista Júlio de Mesquita Filho - Bauru/SP. E-mail: thais.tezani@unesp.br
} 
Keywords: Pandemic. Emergency remote teaching. Distance education.

Resumen: El nuevo coronavirus provocó la pandemia Covid-19, generando una serie de impactos epidemiológicos y socioeconómicos, requiriendo aislamiento social para contener el avance de la enfermedad. Como resultado, se cerraron las escuelas y surgió la educación remota de emergencia, con el objetivo de continuar el aprendizaje de los estudiantes. Así, se realizó una investigación bibliográfica, con el objetivo de analizar las posibilidades de organizar la educación escolar durante la pandemia, las características de la Educación Remota de Emergencia y sus implicaciones para el aprendizaje de los estudiantes. De los resultados señalados, se desprende que las consecuencias son dispares, y aún inconmensurables, ya que la Educación Remota de Emergencia llega solo a una parte de los estudiantes y muestra que es un desafío utilizar las tecnologías digitales como herramientas en el proceso de enseñanza y aprendizaje.

Palabras-clave: Pandemia. Enseñanza remota de emergência. Educación a distancia.

\section{Introdução}

Pensar no processo de ensino e aprendizagem em tempos de pandemia da Covid-19, durante o ano de 2020, tornou-se uma das principais preocupações dos sistemas de ensino, escolas, professores, pais e sociedade. Questões educacionais esquecidas ganharam destaque em virtude do momento de isolamento social, assim ambiguidades, confusões, críticas, desencontros, entre outros aspectos, que estavam esquecidos, foram retomados, como por exemplo, o processo de ensino e aprendizagem mediados pelas tecnologias digitais.

Deste modo, o texto por meio de estudos bibliográficos analisa as possibilidades de organização da educação escolar durante a pandemia, as características do Ensino Remoto Emergencial e suas implicações para a aprendizagem dos alunos, ou seja, tem a proposta de apresentar reflexões, conceitos e incentivar possibilidades de alterações nos processos de ensinar e aprender, conversando com a teoria educacional. Assim, indagamos: $O$ que podemos aprender com tudo isso? Quais lições positivas e negativas esse momento nos proporcionou?

Para isso, inicialmente vamos definir conceitualmente os termos utilizados para não gerar conflito e saber identificar a finalidade de cada um. Num segundo momento realizamos considerações sobre a educação escolar durante a pandemia, as características gerais do Ensino Remoto Emergencial e as possíveis implicações para o processo de ensinar e aprender.

\section{Conhecendo alguns conceitos: educação à distância}

Diante da crise sanitária mundial de 2020, em razão da pandemia da Covid-19, aconteceram mudanças no campo educacional e uma forte pressão tanto no setor público quanto privado pela implantação massiva de atividades por meio das tecnologias digitais nos níveis da Educação Básica à Superior. 
Os sistemas de ensino organizam práticas pedagógicas, contando com as famílias como grandes aliadas, para a execução das atividades em casa, preservando a manutenção da rotina escolar de maneira diferenciada. Porém, para muitos, tudo se transformou em EaD (Educação a Distância), o que é um grande equívoco.

A EaD possui características específicas enquanto modalidade de ensino, são elas:

Tempo e espaço: é uma modalidade de ensino na qual, professores e alunos estão distantes fisicamente no tempo e espaço. Desta maneira, têm-se um novo conceito de sala de aula, e reconfiguração da relação professor $x$ aluno.

Ambiente e tempo são separados: o aluno pode acessar o seu material de estudo em qualquer lugar e a todo o momento. Não havendo as barreiras físicas e temporais.

Permanente - Projeto Pedagógico de Curso: se caracteriza por ser um ensino com um prazo específico (início, meio e fim). Há também o Projeto Político Pedagógico (PPP), como um importante documento, que visa trazer as orientações do curso, as concepções de educação e currículo que irão seguir.

Equipe multidisciplinar: desempenha papel importante, pois gerencia o processo de ensino e aprendizagem on e off-line. É composta por profissionais de distintas áreas, como: designers, tutor, professor-pesquisador, equipe técnica, revisores etc.

Professor: tem a função de produzir e organizar diversos materiais didáticos das disciplinas no Ambiente Virtual de Aprendizagem (AVA), tais como: textos, roteiros de aprendizagem, videoaulas, mas não tem contato direto com os alunos. Também indica as metodologias, recursos e formas de avaliação, sugerindo as tecnologias que melhor se adequam aos objetivos pedagógicos da disciplina (CARGNELUTTI, et al. 2016).

Tutor: "apoiam o trabalho docente, eles são os responsáveis pelo acompanhamento e comunicação sistemática com os alunos. Assim eles são o elo entre a relação professor, curso e aluno" (KONRATH; TAROUCO; BEHAR, 2009, p.4).

Ambiente Virtual de Aprendizagem (AVA): plataforma on-line em que as atividades são postadas, havendo interação do aluno com tutor e com os demais participantes do curso. Possui recursos, como: perfil, chat, fórum de discussão, material de apoio, portfólio, etc.

Ensino em larga escala: como os Massive Open Online Course (MOOC), que contemplam grande público. Possibilitam socialização do aprendizado com baixo custo, favorecendo a formação e capacitação da população. Atendem significativo número de inscrições e podem chegar à milhares de alunos (BARIN; BASTOS, 20I3).

Olhar de professor, Ponta Grossa, v. 24, p. I-9, e-16068.035, 2021.

Disponível em <https://revistas2.uepg.br/index.php/olhardeprofessor> 
Economia - Flexibilidade: o aluno pode aprender em sua casa, sem precisar ter gastos de deslocamento para a instituição de ensino, há também a flexibilidade de estudar nos horários desejados.

Democratização: possibilita a democratização do ensino, visto que alcança números elevados de pessoas em diferentes partes do país.

Evasão: a desistência pode ocorrer por inúmeros motivos: desconhecimento das características da $\mathrm{EaD}$, insatisfação com ○ $\mathrm{AVA}$, dificuldades na comunicação com o tutor, falta de identificação com as tecnologias digitais, etc.

Falta de comprometimento: liberdade de estudo é a grande vantagem da modalidade, porém se o aluno não compreender sua corresponsabilidade, ter disciplina e autonomia, não conseguirá alcançar sucesso na aprendizagem dos conteúdos.

Qualidade: é relativa, pois depende de variáveis, como: materiais didáticos adequados, ferramentas tecnológicas intuitivas, acompanhamento do tutor, etc.

De acordo com Gatti e Barreto (2009), em razão da necessidade massiva de formação de professores, os governos criaram facilidades para a expansão da EaD. Assim, aumentou o número de instituições de ensino privadas que oferecem esses processos formativos on-line, em alguns casos sem condições de oferecer ensino de qualidade, havendo inclusive esvaziamento da formação docente.

Após essa breve explanação sobre as particularidades da $\mathrm{EaD}$, apresentaremos breve discussão a respeito do Ensino Remoto Emergencial que surge neste cenário da pandemia da Covid19.

\section{Ensino remoto emergencial: tecendo considerações}

No ano de 2020, surge um vírus na China que rapidamente se espalhou por todo o mundo. O novo coronavírus causou a Covid-19, que possui facilidade de transmissão, afetando milhares de pessoas e sendo necessário o isolamento social para desacelerar o contágio.

Por isso, foi preciso o fechamento das escolas. A Organização das Nações Unidas (ONU) estima que 9 em cada 10 estudantes estão fora da escola. Em razão disto, houve a necessidade de rápida adaptação por parte dos profissionais da educação, surgindo o Ensino Remoto Emergencial no nosso país, pois esse modelo já havia sido adotado em outros países que vivenciaram catástrofes naturais e/ou guerras civis. Este tipo de ensino assemelha-se a $\mathrm{EaD}$, apenas na questão da mediação por tecnologias digitais, todavia suas premissas são outras.

Olhar de professor, Ponta Grossa, v. 24, p. I-9, e-16068.035, 2021.

Disponível em <https://revistas2.uepg.br/index.php/olhardeprofessor> 
Conforme Costa apud Rabello (2020), no nosso país não havia um plano de contingência educacional ou administrativo para situações assim. As instituições de ensino não estavam preparadas tecnologicamente, teoricamente, nem pedagogicamente para tal situação. $O$ maior desafio recaiu sobre os professores, que precisam adaptar os conteúdos, dinâmicas de sala e avaliações, sem causar danos ao processo de ensino e aprendizagem.

Para dar subsídios à prática docente, as instituições de ensino precisaram apoiar o professor, com instruções claras, definindo modelos e estabelecendo possibilidades para uso das tecnologias digitais. O recomendado é que cada unidade escolar determine o formato das videoaulas, comunicação com os pais, uso e elaboração de materiais didáticos, entre outros.

Hodges et al. (2020) afirma que o Ensino Remoto Emergencial foi uma mudança temporária, um modo de ensino alternativo em razão das circunstâncias de crise sanitária, que fez uso de soluções de ensino totalmente remotas para a instrução, que de outra forma seriam ministradas presencialmente.

Nesse sentido, apresentamos as características do Ensino Remoto Emergencial, que mobiliza ações para que os alunos continuem aprendendo, embora de formas diferentes do convencional.

Replanejamento: os docentes não foram preparados para ensinar on-line e o currículo também não estava adequado para este tipo de ensino. Desta maneira, foram necessárias alterações no calendário escolar, mudanças no calendário escolar, atuação docente e atividades pedagógicas.

Conteúdos: adaptação dos conteúdos para novos modelos, com reformulações para formatos digitais, como videoaulas, atividades on-line e lives.

Estratégias: mudança nos métodos tradicionais de ensino, nos procedimentos pedagógicos, havendo outras maneiras de se relacionar, buscando aproximação com as famílias e diferentes formas de comunicação com os alunos emergiram.

Tecnologias: as tecnologias digitais possibilitaram o contato entre professores e alunos.

Aulas: mudou do presencial para o modelo remoto. Por conseguinte, as Tecnologias Digitais de Informação e Comunicação (TDIC) foram a base para o docente na realização das atividades pedagógicas, para isso recursos, como: WhatsApp, Google Hangout Meet, Skype, Microsoft Teams, foram utilizados.

Ensino temporário: este tipo de ensino não é permanente, tem sua duração estabelecida de acordo com a necessidade, havendo previsão de término.

Conceito novo: é uma nova concepção de educação, nunca vivenciada antes no nosso país.

Aprendizagem: impulsionada pelo uso de metodologias ativas e tecnologias digitais, em que o aluno participa de forma engajada no processo de construção do conhecimento.

Olhar de professor, Ponta Grossa, v. 24, p. I-9, e-16068.035, 2021.

Disponível em <https://revistas2.uepg.br/index.php/olhardeprofessor> 
Professor x Tutor: não há tutor, mas o próprio professor acompanha a sua turma, produz o material adaptado, corrige as atividades e avalia.

Ensino: é um ensino pontual, em que os docentes continuam lecionado para a mesma turma de alunos que atuava no ensino presencial, porém num espaço físico diferente, característica pertencente a $\mathrm{EaD}$, em que "os tempos e espaços da educação tradicional são redimensionados" (MILL, et al. 2008, p. 2).

Lives são outro ponto que se destacaram durante a pandemia. Surgiu, como ferramentas de debates, aquisição de conhecimentos e até mesmo lazer. Por meio de transmissões síncronas de conteúdo em forma de vídeo on-line, podem ser individuais ou coletivas, tendo interação direta em várias plataformas e redes sociais. No meio acadêmico, reconfiguram o ciberespaço, eventos científicos, como: conferências, palestras, rodas de conversa, encontros de grupo de pesquisa, aulas, entrevistas (SANTOS, 2020).

Ainda de acordo com as ideias da autora citada, a comunicação síncrona (aquela que ocorre em tempo real) é uma característica marcante das Lives. No entanto, também tem seu aspecto de assíncrona (acesso não simultâneo), já que podem ser gravadas e disponibilizadas em diferentes plataformas. Esse armazenamento em suporte digital, a torna um "artefato curricular" e/ou cultural, pois se pode reutilizá-las em aulas, cursos e/ou momentos de estudo.

Em um período de distanciamento social, o Ensino Remoto Emergencial, surge como uma possibilidade para que os alunos sigam com seus aprendizados, entretanto ressaltamos que há alunos que não tem acesso à internet e os sistemas de ensino, buscaram alternativas para disponibilizar materiais para todos. Medidas foram realizadas, como a impressão de apostilas e materiais pedagógicos.

\section{Refletindo sobre possibilidades}

O Ensino Remoto Emergencial não substitui o presencial, mas não há como negar que sua articulação com as tecnologias digitais trará alterações para o processo de ensino e aprendizagem. Obviamente não é possível realizar uma transformação educacional e digital em um curto período de tempo, todavia professores se reinventaram e conteúdos foram adaptados, ou seja, métodos e estratégias educacionais renovadas.

Desta forma, realizamos algumas reflexões acerca deste tipo de ensino.

a) Escolas precisam diversificar suas metodologias, buscando integrá-las com as tecnologias digitais, tornando o ensino mais dinâmico, diversificado e favorecendo o protagonismo estudantil. 
b) Pais necessitam acompanhar os filhos em suas aprendizagens, sendo presentes em sua formação intelectual, de modo a valorizar a educação escolar.

c) Sistemas de ensino brasileiros carecem de inovações de estratégias múltiplas para adaptação aos diversos contextos, conforme indica o desempenho escolar dos estudantes, de modo a fortalecer o processo de ensino e aprendizagem e diminuir a repetência e/ou evasão escolar, fomentando também nos cursos de formação de professores o uso das tecnologias digitais. Tais pressupostos são evidenciados com o desempenho dos estudantes brasileiros em avaliações internacionais. Conforme Zompero, Figueiredo e Vieira (2016), o Brasil ficou em $60^{\circ}$ lugar no ranking, do exame realizado em 2015 do Programa Internacional de Avaliação de Estudantes (PISA).

Portanto, diante da conjuntura tiramos algumas lições: as possibilidades que as tecnologias digitais podem oferecer para o processo de ensinar e aprender, favorecendo a compreensão dos alunos a aprenderem os conteúdos curriculares.

Assim, o digital se torna capaz de proporcionar a inovação da prática docente, uma vez que o professor pode fazer $\circ$ uso de metodologias diferenciadas e ativas. $O$ que estamos vivendo é a reinvenção da educação escolar em tempos de pandemia. $\mathrm{Na}$ escola pública a problemática acentuase ainda mais, com a dificuldade de acesso às atividades, professores com pouca formação tecnológica e escassos recursos materiais. Sem uma coordenação nacional que apresente diretrizes condizentes e coerentes para organização das atividades escolares, a escola pública de Educação Básica ficará extremamente prejudicada.

A análise crítica da desigualdade cada vez maior entre os sistemas de ensino (público e privado) é outra lição que aprendemos. O Ensino Remoto Emergencial exacerbou uma situação triste e preocupante: o fosso entre o ensino público e particular, em específico na Educação Básica. As ações planejadas e assertivas precisam ser elaboradas em breve para que a escola pública se fortaleça e possa encontrar alternativas de atuação diante de situações adversas de modo a garantir os direitos legais das crianças em idade escolar.

Ao retornarem as aulas presenciais, os sistemas de ensino não podem ignorar a relevância das tecnologias digitais, sendo necessárias políticas públicas que invistam em infraestrutura tecnológica nos ambientes educacionais. Outro ponto que não pode cair no esquecimento, é a respeito da formação docente, já que se faz necessário o desenvolvimento das competências digitais para que professores possam incorporar as tecnologias em sua prática pedagógica.

\section{Considerações finais}

A pandemia da Covid-19 gerou efeitos internacionais, contribuindo para uma crise epidemiológica e socioeconômica, com fortes sequelas, evidenciando a falta de preparo dos estados e 
governos em administrar a situação. Por se tratar de um assunto ainda em vigência, não há estudos científicos que direcionam medidas eficazes para conter o surto epidêmico, nem alternativas de ensino que possam ser implementadas para garantir o sucesso do aprendizado dos alunos.

O cenário inesperado explicitou as desigualdades em diversas áreas: econômica, social e principalmente educacional, uma vez que a tendência é reproduzir de modo amplificado as estratégias de ensino por meio das tecnologias digitais, porém não são totalmente acessíveis para todos os estudantes e professores.

Diante disso, é necessário repensar a educação escolar, a formação de professores, o valor social da educação e da escola. Trata-se de um momento de reflexão para que os rumos da educação escolar brasileira sejam revistos: olhar para o passado, viver o presente e, principalmente, pensar no futuro.

\section{Referências}

BARIN, C. S.; BASTOS, F. da P. de. Problematização dos MOOC na atualidade: Potencialidades e Desafios. CINTED-UFRGS Novas Tecnologias na Educação. v. II $n^{\circ} 3$, dezembro, 2013. Disponível em: <https://www.seer.ufrgs.br/renote/article/view/44707/28546>. Acesso em: 04 de jun. 2020.

CARGNELUTTI, C. M. et al. Educadores e profissionais na EaD: o processo de produção de materiais didáticos em uma Equipe Multidisciplinar. SIED: EnPED. Simpósio Internacional de Educação a Distância e Encontro de Pesquisadores em Educação a Distância, 2016. Disponível em: <http://www.sied-enped2016.ead.ufscar.br/ojs/index.php/2016/article/view/l376/566>. Acesso em: 04 de jun. 2020.

GATTI, B. A. BARRETO, E. S. de S. Professores no Brasil: impasses e desafios. 2009. Organização das Nações Unidas para a Educação, a Ciência e a Cultura. Brasília: UNESCO, 2009. Disponível em: $<$ https://www.fcc.org.br/fcc/wp-content/uploads/2019/04/Professores-do-Brasil-impasses-edesafios.pdf $>$. Acesso em: 04 de jun. 2020.

HODGES, C. et al. The Difference Between Emergency Remote Teaching and Online Learning. Revista Educause. 2020. Disponível em: <https://er.educause.edu/articles/2020/3/the-differencebetween-emergency-remote-teaching-and-online-learning\#fn I>. Acesso em: 28 maio 2020.

KONRATH, M. L. P.; TAROUCO, L. M. R.; BEHAR, P. A. Competências: desafios para alunos, tutores e professores da EaD. Revista RENOTE - Novas Tecnologias na Educação, v.7, n.I, p. I10, 2009. Disponível em: <https://www.seer.ufrgs.br/renote/article/view/I39/2/78/9>. Acesso em: 04 de jun. 2020.

MILL, D. et. al. O desafio de uma interação de qualidade na educação a distância: o tutor e sua importância nesse processo. Cadernos da Pedagogia, São Carlos, v. 2, n. 4, p. II2-I27, ago./dez. 2008.

RABELLO, M. E. Lições do coronavírus: ensino remoto emergencial não é EAD. Revista Desafios da Educação. Abril/ 2020. Disponível: <https://desafiosdaeducacao.grupoa.com.br/coronavirusensino-remoto/>. Acesso em: 05 de jun. 2020. 
SANTOS, E. Notícias: \#livesdemaio... Educações em tempos de pandemia. Revista Docência e Cibercultura. Seção Notícias. Junho/2020. Disponível em: <https://www.epublicacoes.uerj.br/index.php/re-doc/announcement/view/I I09> Acesso em: 04 de jun. 2020.

ZOMPERO, A. F.; FIGUEIREDO, H. R. S.; VIEIRA, K.A. O desempenho de alunos brasileiros e a avaliação pisa: alguns aspectos para discussão. Góndola, Enseñ Aprend Cienc, Vol. II, n. I, p.8699 2016.

Disponível em: $<$ https://revistas.udistrital.edu.co/index.php/GDLA/article/view/9259/II556>. Acesso em: 29 de mar. 2020.

Recebido em: I5 de junho de 2020.

Versão corrigida recebida em: 03 de fevereiro de 2021.

Aceito em: 03 de fevereiro de 202I.

Publicado online em: 23 de abril de 202I.

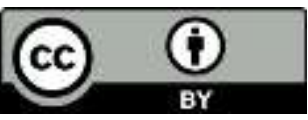

